\title{
Competitive Adsorption of Cadmium (II) from Aqueous Solutions onto Nanoparticles of Water Treatment Residual
}

\author{
Elsayed Elkhatib, Ahmed Mahdy, Fatma Sherif, and Walaa Elshemy \\ Department of Soil and Water Sciences, Alexandria University, Alexandria 21545, Egypt \\ Correspondence should be addressed to Elsayed Elkhatib; selkhatib1@yahoo.com
}

Received 21 May 2016; Revised 18 July 2016; Accepted 19 July 2016

Academic Editor: William Yu

Copyright (C) 2016 Elsayed Elkhatib et al. This is an open access article distributed under the Creative Commons Attribution License, which permits unrestricted use, distribution, and reproduction in any medium, provided the original work is properly cited.

\begin{abstract}
There is increasing interest in using water treatment residuals (WTRs) for heavy metals removal from wastewater due to their low cost, availability, and high efficiency in removing various pollutants. In this study, novel water treatment residuals nanoparticles (nWTRs) were prepared using high energy ball milling and used for efficient removal of Cd(II) in single- and multi-ion systems. The WTR nanoparticles demonstrated high removal efficiency for Cd from aqueous solution as the adsorption capacities of nWTR were 17 and 10 times higher than those of bulk WTR in single- and multielement systems, respectively. Noticeably, Cd(II) adsorption was clearly suppressed in the multi-ion system as $\mathrm{Cu}$ and $\mathrm{Pb}$ form the most stable monohydroxo complexes. Fourier transmission infrared (FTIR) analyses suggested the participation of $\mathrm{OH}^{-}, \mathrm{O}-\mathrm{Al}-\mathrm{O}, \mathrm{FeOH}$, and $\mathrm{FeOOH}$ entities in the adsorption process. The stability of Cd-nWTR surface complexes is evident as less than $0.2 \%$ of adsorbed Cd(ll) was released at the highest Cd(II) concentration load after 4 consecutive desorption cycles. Moreover, the real efficiency of nWTR for Cd(II) removal from wastewater samples studied was calculated to be $98.35 \%$. These results highlight the potential of nWTR for heavy metals removal from wastewater.
\end{abstract}

\section{Introduction}

Aquatic ecosystems contamination especially with heavy metal ions is an environmental problem worldwide. Of all contaminant metals, cadmium is considered an extremely toxic heavy metal with acceptable levels one-tenth those of most of the other toxic metals $[1,2]$. Cadmium pollution arises mainly from domestic sewage and the effluents of industries involved in electroplating, smelting, alloy manufacturing, pigments, plastic, cadmium-nickel batteries, fertilizers, pesticides, pigments and dyes, textile operations, and refining $[3,4]$. The main form of $\mathrm{Cd}$ in contaminated water is $\mathrm{Cd}(\mathrm{II})$ and the remediation technologies available to reduce $\mathrm{Cd}$ concentrations in contaminated water systems include ion-exchange, solvent extraction, chemical precipitation, phytoextraction, ultrafiltration, reverse osmosis, electrodialysis, and adsorption [3-6].

However, most of these technologies have shown limitations in removing the toxic contaminants from contaminated water to safe levels and they are costly, laborious, and time-consuming $[7,8]$. Development of cheap and green remediation technology is urgently needed. Water treatment residuals (WTRs), waste material resulting from the treatment of surface water with $\mathrm{Al}$ and $\mathrm{Fe}$ salts, have been gaining increased attention recently as an eco-friendly and low cost adsorbent. Because of their amorphous nature, WTRs have shown strong affinity for $\mathrm{Ni}, \mathrm{Cu}, \mathrm{Pb}$, and $\mathrm{Hg}$ [9-12].

Moreover, conclusive evidences have demonstrated that the smaller size fraction of WTRs greatly increases their active surface area and adsorption performance [13]. Recently, Elkhatib et al. [14] developed a method to produce nanoscale sorbent from water treatment residues using ball milling. They demonstrated that the removal efficiency of the produced nanoparticles for As was 16 times higher than the removal efficiency of bulk WTR [15].

The greater adsorption capacity of water treatment residuals nanoparticles (nWTRs) in comparison with larger particles suggests their use as a very promising candidate for contaminated water and wastewater remediation. The potential use of bulk WTRs, inexpensive and nonhazardous waste material, was already tested for the removal of many metals in literature [16]. 
TABLE 1: Some physical and chemical characteristics of studied drinking water treatment residuals (WTRs).

\begin{tabular}{lcc}
\hline Characteristics $^{\ddagger}$ & Units & $\mathrm{WTRs}^{\dagger}$ \\
\hline $\mathrm{pH}$ & & $7.45 \pm 0.06$ \\
$\mathrm{EC}$ & $\mathrm{dS} \mathrm{m}$ & $1.67 \pm 0.04$ \\
$\mathrm{O}^{-1}$ & $\mathrm{~g} \mathrm{~kg}^{-1}$ & $57.00 \pm 2.00$ \\
$\mathrm{KCl}-\mathrm{Al}$ & $\mathrm{mg} \mathrm{kg}^{-1}$ & $28.18 \pm 1.03$ \\
Olsen-P & $\mathrm{mg} \mathrm{kg}^{-1}$ & $24.00 \pm 2.00$ \\
$\mathrm{CEC}$ & $\mathrm{Cmol}^{+}+\mathrm{kg}^{-1}$ & $34.78 \pm 0.34$ \\
Total elements & & \\
$\mathrm{N}$ & $\mathrm{g} \mathrm{kg}^{-1}$ & $4.20 \pm 0.13$ \\
$\mathrm{P}$ & $\mathrm{g} \mathrm{kg}^{-1}$ & $1.90 \pm 0.15$ \\
$\mathrm{~K}$ & $\mathrm{~g} \mathrm{~kg}^{-1}$ & $2.20 \pm 0.21$ \\
$\mathrm{Al}$ & $\mathrm{g} \mathrm{kg}^{-1}$ & $38.01 \pm 0.93$ \\
$\mathrm{Ni}$ & $\mathrm{mg} \mathrm{kg}^{-1}$ & $9.40 \pm 0.07$ \\
$\mathrm{~Pb}$ & $\mathrm{mg} \mathrm{kg}^{-1}$ & $76.00 \pm 0.17$ \\
$\mathrm{Cu}$ & $\mathrm{mg} \mathrm{kg}^{-1}$ & $49.00 \pm 0.02$ \\
$\mathrm{Hg}$ & $\mathrm{mg} \mathrm{kg}^{-1}$ & $1.04 \pm 0.02$ \\
\hline
\end{tabular}

${ }^{\dagger}$ Means of three samples \pm SD. ${ }^{\ddagger}$ EC: elctric conductivity; O.M: organic matter; CEC: cation exchange capacity.

However, information is not available in the literature on the use of nanoscale WTR as super adsorbent for cadmium (II) removal. Here we report a comparative study of bulk WTRs and WTR nanoparticles for treatment of $\mathrm{Cd}(\mathrm{II})$ contaminated water. The objectives of this study were therefore (i) to determine cadmium adsorption capacity of water treatment residual nanoparticles and to investigate the pertinent adsorption mechanism and (ii) to study the effects of operational parameters including adsorbent dosages, solution $\mathrm{pH}$, and competing cations on the removal of $\mathrm{Cd}$ by nWTRs. Such a study is important to throw the lights on nanoscale WTRs as a remediation agent for wastewater and freshwater.

\section{Experimental}

2.1. Synthesis and Characterization of Water Treatment Residuals Nanparticles (nWTRs). The bulk WTR (mWTR) was obtained from the drinking water treatment plant in Kafr ElDawar, El-Behera, Egypt. The mWTR samples were collected from the treatment plant disposal site (open dry land in the close vicinity of the water treatment plant) using a shovel. The samples were transferred into high density polyethylene containers and transported to the laboratory at Alexandria University. The selected physical and chemical characteristics of the studied drinking water treatment residuals (WTRs) are shown in Table 1.

In the laboratory, mWTRs samples were first air-dried at room temperature for a period of 4 weeks. Relatively homogeneous material was obtained by passing dried mWTR through two different sieves having $2 \mathrm{~mm}$ and $51 \mathrm{um}$ of pore diameters.
Synthesis of water treatment residuals nanoparticles (nWTRs) was achieved by milling subsamples of uWTR ( $<51 \mathrm{um}$ ) using Fritsch planetary mono mill [14]. The characteristics and element contents of nWTR, mWTR, and uWTR were investigated using scanning electron microscopy (SEM) with energy dispersive X-ray (INCAx-Sight model 6587, Oxford Instruments, UK) and Autosorb-iQ surface area analyzer (Quantachrome, USA) and the results have been reported elsewhere [14].

2.2. Sorption Isotherms and Maximum Sorption Capacity of $n W T R s$. Batch sorption experiments were carried out in $50 \mathrm{~mL}$ polypropylene centrifuge tubes using three sizes of WTR $(2 \mathrm{~mm}$, less than 51 microns, and less than $100 \mathrm{~nm}$ ). The Cd concentrations used in all batch sorption experiments ranged from 0 to $160 \mathrm{mg} \mathrm{Cd} / \mathrm{L}$ in a background electrolyte of $0.01 \mathrm{M} \mathrm{K}_{2} \mathrm{SO}_{4}$. The WTR-Cd mixtures were equilibrated on a slowly end-over-end shaker ( $4 \mathrm{rpm})$ for $24 \mathrm{~h}$ and centrifuged at $4000 \mathrm{rpm}$ for $20 \mathrm{~min}$ and the obtained supernatant solutions were filtered through a $0.45 \mu \mathrm{m}$ Millipore filter. All experiments were performed in triplicate, and solutions were analyzed for Cd by inductively coupled plasma spectrometry (ICPS). The sorption data were then fitted to different isotherm models and the best fit was used to calculate the maximum sorption capacity. The solid nWTR material used in these sorption experiments was recovered and examined for sorbed Cd via scanning electron microscopy equipped with an X-ray energy dispersive spectrometer (SEM-EDX).

2.3. Competitive Adsorption Behavior. In reality, the presence of multiple competing ions is more frequent than the existence of only one kind of ion. Therefore, to assess competition for adsorption sites, multi-ion solutions were prepared and tested. Solutions containing equal amounts of $\mathrm{Pb}, \mathrm{Cd}$, and $\mathrm{Cu}$ (multi-ion system) ranging from 5 to $160 \mathrm{mg} / \mathrm{L}$ were prepared in $0.01 \mathrm{M} \mathrm{K}_{2} \mathrm{SO}_{4}$ background electrolyte and mixed with nWTRs. The suspensions were equilibrated for $24 \mathrm{~h}$, after which aliquots were collected, centrifuged, and filtered through $0.45 \mathrm{um}$.

2.4. Sorption Kinetics and Effect of pH. A sufficient mass of nanoscale water treatment residuals was used in $0.01 \mathrm{M}$ $\mathrm{K}_{2} \mathrm{SO}_{4}$ background electrolyte. Adsorption experiments as a function of time and $\mathrm{pH}$ (adsorption edge) were conducted in single-ion and multi-ion systems. The equilibrium $\mathrm{pH}$ of the suspension used varied from 5.0 to 9.0 with a $2.0 \mathrm{pH}$ unit increment using combined $\mathrm{pH}$ electrode with standard $\mathrm{pH}$ buffers. The suspensions were equilibrated for $\mathrm{Cd}$ adsorption for $24 \mathrm{~h}$ and an aliquot was collected at $5 \mathrm{~min}, 30 \mathrm{~min}, 1 \mathrm{~h}, 4 \mathrm{~h}$, $8 \mathrm{~h}$, and $24 \mathrm{~h}$ contact time. The aliquots were centrifuged and filtered through $0.45 \mathrm{um}$ Millipore filter and the supernatant was analyzed for $\mathrm{Cd}$ using ICP. The amount of $\mathrm{Cd}$ adsorbed was calculated as the difference between the initial and final metal concentrations and the obtained data were fitted into different kinetic models.

2.5. Effect of Initial Metal Concentration and nWTR Dose. The effects of initial metal concentration and nWTR dose 


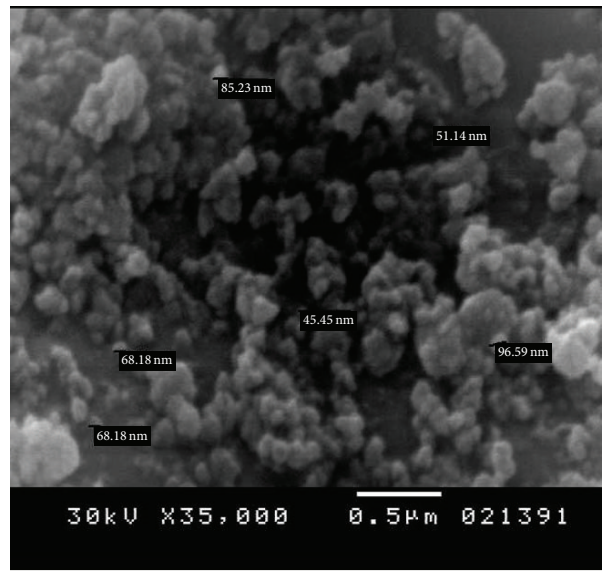

(a)

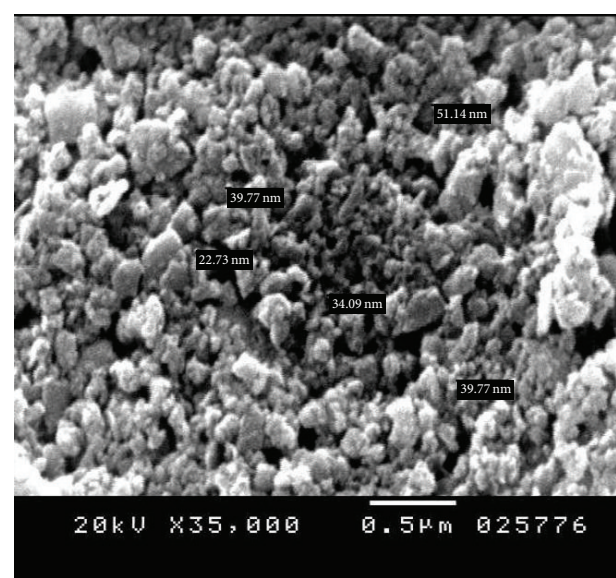

(b)

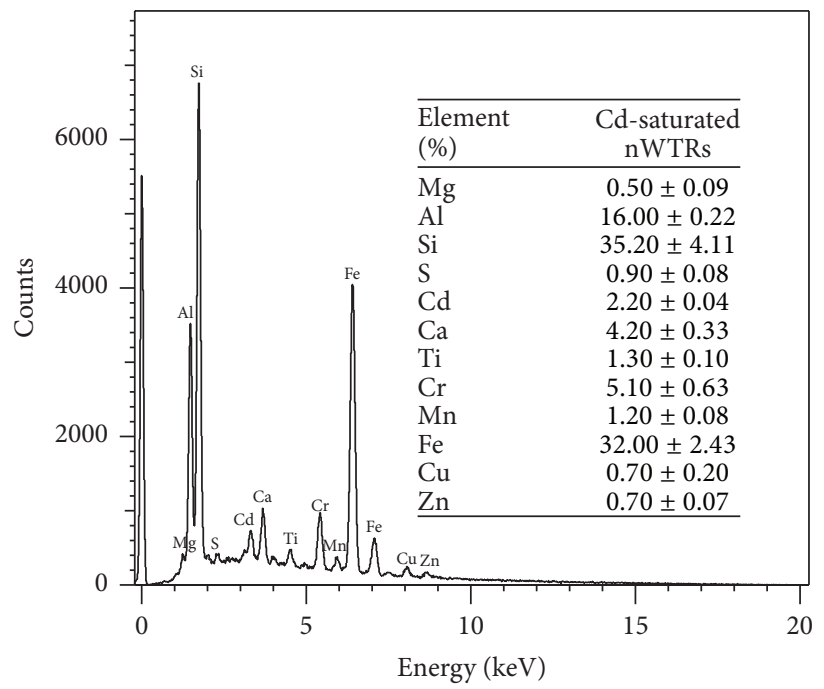

(c)

FIGURE 1: Scanning electron microscopy (SEM) image spectrum of (a) nWTR, (b) the Cd-loaded nWTR, and (c) energy dispersive X-ray (EDX) of Cd-loaded nWTR.

on the extent of adsorption were investigated at the initial metal concentrations of 10.0, 50.0, 200.0, and $500.0 \mathrm{mg} / \mathrm{L}$. The experiments were performed by adding $0.02 \mathrm{~g}, 0.05 \mathrm{~g}$, or $0.10 \mathrm{~g}$ of nWTR sample into $10.0 \mathrm{~mL}$ potions of $\mathrm{Cd}$ solutions. The mixtures were equilibrated for 24.0 hours and then removed for centrifugation. After centrifugation, the supernatant solutions were retransferred into clean falcon tubes, acidified, and kept in the refrigerator until analysis.

2.6. Desorption Studies. In order to assess the stability of adsorption, $10.0 \mathrm{~mL}$ portions of high purity water were added onto Cd-loaded nWTR (after sorption experiment) and were shaken for 24 hours. After separation of liquid and solid phases by centrifugation, the solutions were acidified and kept in the refrigerator until Cd analysis.

\section{Results and Discussion}

3.1. Characterization of Bulk WTR and nWTR. The mi crostructure of WTR nanoparticles as examined by SEM indicated that WTR nanoparticles are spherical and the representative single particle sizes are typically less than $100 \mathrm{~nm}$ in diameter (Figure 1(a)). The major elements in nWTR as revealed by SEM-EDX are $\mathrm{Si}, \mathrm{Al}$, and $\mathrm{Fe}$, and they represent around $83 \%$ of the total elements (Figure 1(a)). The X-ray diffraction analysis [15] suggested that amorphous iron, aluminum (hydr) oxides, and silicon oxide dominated all nWTR, with no apparent crystalline iron-Al (hydr) oxides. After the reaction with $\mathrm{Cd}$ ions, the SEM image of nWTR (Figure 1(b)) shows formation of a coating layer on the surface of the nWTR which indicates that the reaction occurred on the surface of nWTR. In addition, the SEM-EDX analysis spectrum (Figure 1(b)) ascertained the appearance of a cadmium peak (2.20\%) amongst the elements detected in Cd-saturated nWTR. The BET specific surface area (SSA) of nWTR sample revealed that SSA of nanoscale WTR $\left(129.0 \mathrm{~m}^{2} \mathrm{~g}^{-1}\right)$ is 2-3 times higher than SSA of mWTR $\left(53.1 \mathrm{~m}^{2} \mathrm{~g}^{-1}\right)$ which demonstrates the high reactivity of nWTR and makes it ideal candidate for water treatment and desalination. 


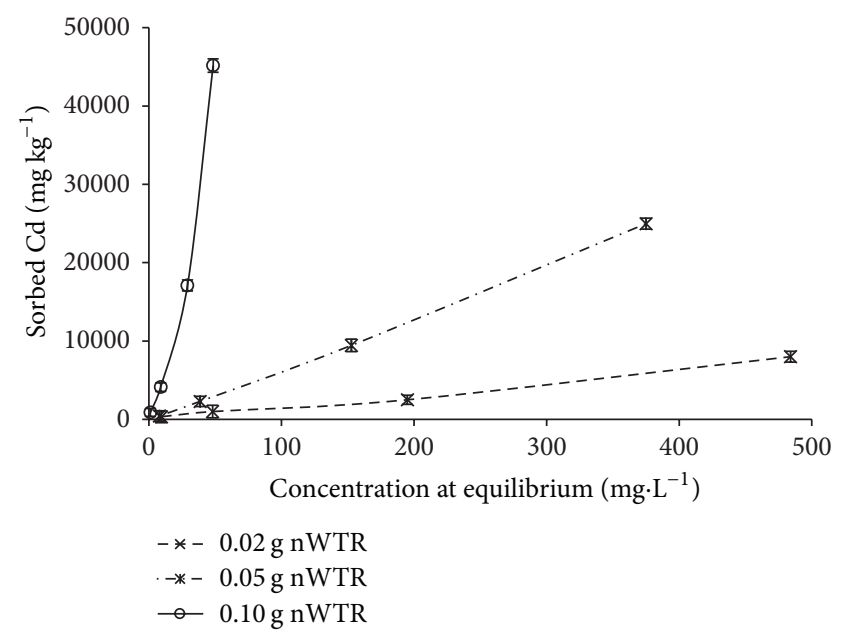

FIGURE 2: Effect of adsorbent dose on adsorption of Cd(II) by nWTR.

3.2. Effect of Adsorbent Dose. The effect of nWTR dose on $\mathrm{Cd}$ removal from solutions at different $\mathrm{Cd}$ concentrations is shown in Figure 2. The $\mathrm{Cd}^{2+}$ adsorption efficiency increases with increasing adsorbent dose of nWTR from 0.02 to $0.10 \mathrm{~g}$. The amount of $\mathrm{Cd}^{2+}$ adsorbed increased from $900 \mathrm{mg} \mathrm{kg}^{-1}$ at $0.02 \mathrm{~g}$ to $46,000 \mathrm{mg} \mathrm{kg}^{-1} \mathrm{nWTR}$ at $0.10 \mathrm{~g}$. The H-type adsorption isotherm of nWTR $(0.10 \mathrm{~g} / \mathrm{L})$ dose suggests a very strong metal-nWTR surface interaction [17]. The enhanced adsorption with increasing adsorbent dose is attributed to higher surface area and the more adsorption sites available at higher adsorbent dose. Therefore, the nWTR dose of $0.10 \mathrm{~g}$ was proposed as optimum nWTR dose required for efficient $\mathrm{Cd}$ removal at different initial Cd concentrations. The nWTR dose of $0.10 \mathrm{~g}$ was used in subsequent experiments.

3.3. Equilibrium Studies. The data of Cd adsorption onto three different particle sizes of WTR in single- and multielement systems were analyzed using seven isotherm models: Langmuir, Freundlich, Temkin, Fowler-Guggenheim, Kiselev, Elovich, and Hill-de Boer.

\section{Equilibrium and Kinetic Models}

\section{Equilibrium Models}

Freundlich

$$
q_{e}=K_{F} C_{e}^{1 / n}
$$

Langmuir

$$
q_{e}=q_{\max }\left(\frac{K_{L} C_{e}}{1+K_{L} C_{e}}\right) .
$$

Elovich isotherm model

$$
\frac{q_{e}}{q_{\max }}=K_{E} C_{e} \exp \left(\frac{-q_{e}}{q_{\max }}\right) \text {. }
$$

Temkin

$$
\theta=\frac{R T}{\Delta Q \ln K_{0} C_{e}}
$$

Fowler-Guggenheim (FG)

$$
K_{\mathrm{FG}} C_{e}=\frac{\theta}{1-\theta} \exp \left(\frac{2 \theta w}{R T}\right) .
$$

Kiselev

$$
k_{1} C_{e}=\frac{\theta}{(1-\theta)\left(1+k_{n} \theta\right)} .
$$

Hill-de Boer

$$
K_{1} C_{e}=\frac{\theta}{(1-\theta)} \exp \left(\frac{\theta}{(1-\theta)}-\frac{K_{2} \theta}{R T}\right),
$$

where $K_{F}$ is relative adsorption capacity of the adsorbent $\left(\mathrm{mg}^{1-1 / n}\right) \mathrm{L}^{1 / n} \mathrm{~g}^{-1}, n$ is constant and measures the strength of adsorption, $q_{e}$ is amount of $\mathrm{Cd}$ adsorbed per gram of adsorbent, $C_{e}$ is equilibrium concentration in the bulk solution, $q_{\max }$ is maximum adsorption capacity of the adsorbent, $K_{L}$ is Langmuir constant related to the free energy of adsorption, $K_{E}$ is Elovich equilibrium constant, $\theta$ is fractional coverage, $R$ is universal gas constant $\left(\mathrm{kJ} \mathrm{mol}^{-1} \mathrm{~K}^{-1}\right), \Delta Q$ is $(-\Delta H)$ the variation of adsorption energy $\left(\mathrm{kJ} \mathrm{mol}^{-1}\right), K_{0}$ is Temkin equilibrium constant $\left(\mathrm{L} \mathrm{mg}^{-1}\right), K_{\mathrm{FG}}$ is Fowler-Guggenheim equilibrium constant $\left(\mathrm{L} \mathrm{mg}^{-1}\right), T$ is temperature $(\mathrm{K}), w$ is interaction energy between adsorbed molecules $\left(\mathrm{kJ} \mathrm{mol}^{-1}\right)$, $k_{1}$ is Kiselev equilibrium constant $\left(\mathrm{L} \mathrm{mg}^{-1}\right), k_{n}$ is constant of complex formation between adsorbed molecules, $K_{1}$ is Hill-de Boer constant $\left(\mathrm{L} \mathrm{mg}^{-1}\right), K_{2}$ is energetic interaction between adsorbed molecules $\left(\mathrm{kJ} \mathrm{mol}^{-1}\right)$.

\section{Kinetics Models}

Elovich

$$
q=\left(\frac{1}{\beta}\right) \ln (\alpha \beta)+\left(\frac{1}{\beta}\right) \ln t .
$$

Intraparticle diffusion

$$
q=k_{a} t^{1 / 2} .
$$

Power function

$$
q=k t^{v}
$$

First-order model

$$
\ln \left(q_{o}-q\right)=a-k_{a} t,
$$

where $q$ is amount of Cd adsorbed per gram of adsorbent in time $t, \alpha$ is initial adsorption rate $\left(\mathrm{mg} \mathrm{min}^{-1}\right), \beta$ is a constant related to surface coverage and activation energy, $k_{a}$ 
TABLE 2: Equilibrium model parameters and determination coefficients $\left(R^{2}\right)$ and standard error of estimate (SE) for cadmium adsorption by nWTR in single-ion and multi-ion systems.

\begin{tabular}{|c|c|c|c|c|c|c|c|}
\hline \multirow{2}{*}{ Model } & \multirow{2}{*}{ Parameter } & \multicolumn{2}{|c|}{ nWTRs } & \multicolumn{2}{|c|}{$\mu \mathrm{WTRs}$} & \multicolumn{2}{|c|}{ mWTRs } \\
\hline & & Single-ion & Multi-ion & Single-ion & Multi-ion & Single-ion & Multi-ion \\
\hline \multirow{4}{*}{ Langmuir } & $q_{\max }\left(\mathrm{mgg}^{-1}\right)$ & 47 & 16.67 & 4.60 & 2.50 & 2.80 & 1.75 \\
\hline & $K_{L}\left(\mathrm{~L} \mathrm{mg}^{-1}\right)$ & 53.19 & 117 & 24.15 & 235.85 & 0.36 & 223 \\
\hline & $R^{2}$ & 0.96 & 0.86 & 0.95 & 0.81 & 0.95 & 0.78 \\
\hline & SE & $9.46 \times 10^{-5}$ & $1.5 \times 10^{-3}$ & 0.001 & $1.1 \times 10^{-2}$ & 0.001 & $1.9 \times 10^{-2}$ \\
\hline \multirow{4}{*}{ Freundlich } & $K_{F}\left(\mathrm{~mL} \mathrm{~g}^{-1}\right)$ & 18928 & 171.5 & 549.44 & 12.4 & 205.6 & 9.71 \\
\hline & $1 / n$ & 0.401 & 0.848 & 0.1736 & 0.898 & 0.39 & 0.880 \\
\hline & $R^{2}$ & 0.94 & 0.96 & 0.91 & 0.98 & 0.97 & 0.98 \\
\hline & SE & 0.31 & 0.255 & 0.35 & 0.162 & 0.18 & 0.163 \\
\hline \multirow{4}{*}{ Elovich } & $q_{\max }\left(\mu g g^{-1}\right)$ & 33333 & 10000 & 2000 & 500 & 1250 & 2000 \\
\hline & $K_{E}\left(\mathrm{~L} \mathrm{mg}^{-1}\right)$ & 4.21 & 1.00 & 0.129 & 0.99 & 0.089 & 0.99 \\
\hline & $R^{2}$ & 0.96 & 0.92 & 0.89 & 0.42 & 0.95 & 0.02 \\
\hline & SE & 0.10 & 0.125 & 0.21 & 1.32 & 0.14 & 1.23 \\
\hline \multirow{4}{*}{ Temkin } & $\Delta Q\left(\mathrm{~kJ} \mathrm{~mol}{ }^{-1}\right)$ & 0.771 & 0.92 & 22 & 48 & 17 & 24 \\
\hline & $K_{0}\left(\mathrm{~L} \mathrm{mg}^{-1}\right)$ & 1.33 & 1.34 & 1.42 & 1.01 & 3.45 & 5.46 \\
\hline & $R^{2}$ & 0.96 & 0.97 & 0.93 & 0.68 & 0.85 & 0.87 \\
\hline & SE & 0.054 & 0.035 & 0.056 & 0.088 & 0.1 & 0.063 \\
\hline \multirow{4}{*}{ Fowler-Guggenheim } & $W\left(\mathrm{~kJ} \mathrm{~mol}^{-1}\right)$ & 0.736 & 0.917 & 1.31 & 1.38 & 6.58 & 10.46 \\
\hline & $K_{\mathrm{FG}}\left(\mathrm{L} \mathrm{mg}^{-1}\right)$ & 0.556 & 1.86 & 0.023 & 0.035 & 0.106 & 0.131 \\
\hline & $R^{2}$ & 0.93 & 0.99 & 0.94 & 0.94 & 0.90 & 0.97 \\
\hline & SE & 0.047 & 0.016 & 0.048 & 0.044 & 0.48 & 0.247 \\
\hline \multirow{4}{*}{ Kiselev } & $k_{n}$ & 5.256 & -0.697 & 6.029 & 1.18 & 4.83 & -0.177 \\
\hline & $K_{1}\left(\mathrm{~L} \mathrm{mg}^{-1}\right)$ & 44.07 & 0.008 & 22.26 & 0.004 & 0.281 & 0.004 \\
\hline & $R^{2}$ & 0.96 & 0.99 & 0.95 & 0.99 & 0.95 & 0.99 \\
\hline & SE & 213 & 0.005 & 118 & 0.007 & 0.97 & 0.004 \\
\hline \multirow{4}{*}{ Hill-de Boer } & $K_{1}\left(\mathrm{~L} \mathrm{mg}^{-1}\right)$ & 0.354 & 2.98 & 0.036 & 0.008 & 0.003 & 0.005 \\
\hline & $K_{2}\left(\mathrm{~kJ} \mathrm{~mol}^{-1}\right)$ & 2.496 & -3.023 & 3.846 & 15.073 & 14.6 & 4.078 \\
\hline & $R^{2}$ & 0.96 & 0.96 & 0.98 & 0.38 & 0.99 & 0.69 \\
\hline & SE & 0.06 & 0.053 & 0.04 & 1.238 & 0.10 & 0.194 \\
\hline
\end{tabular}

is apparent sorption diffusion rate coefficient $\left(\mu \mathrm{g} \mathrm{g}^{-1} \mathrm{~min}^{-1}\right)$, $t$ is reaction time $(\mathrm{min}), k$ is a constant $\left(\mathrm{mg} \mathrm{g}^{-1}\right), v$ is estimated apparent sorption rate $\left(\mathrm{min}^{-1}\right), q_{o}$ is amount of $\mathrm{Cd}$ adsorption at equilibrium, $k_{a}$ is apparent adsorption rate coefficient.

The experimental data were fitted to the seven isotherm models tested using linear forms [18]. Model parameters as well as coefficient determination $\left(R^{2}\right)$ and the standard error of estimate (SE) values of all models are presented in Equilibrium and Kinetic Models. $R^{2}$ of all models tested were quite high especially for nWTR. Comparing goodness-offit measures between the different 7 models tested shows that Langmuir model yielded the lowest SE values for all the sorbents followed by Temkin and Fowler-Guggenheim models (Equilibrium and Kinetic Models). The high SE values of Freundlich, Hill-de Boer, Elovich, and Kiselev models indicate the low predictive ability of these models to describe Cd sorption date (Table 2). Therefore, in the following, we will refer only to the results of the Langmuir isotherm model.

3.3.1. Langmuir Isotherm Model. Cadmium sorption conformed to the Langmuir model over the entire concentration range for all three particle sizes of WTR in both single- and multielement systems (Table 2 and Figure 3). The goodnessof-fit of Langmuir model suggested the homogeneous and monolayer mode of adsorption. The calculated Langmuir $q_{\max }$ values for mWTR, uWTR, and nWTR in single-ion system were $2.8,4.6$, and $47 \mathrm{mg} \mathrm{Cd} \mathrm{g}^{-1}$, respectively (Table 1). In multielement system, Langmuir $q_{\max }$ values were 1.75 , 2.50, and $16.67 \mathrm{mg} \mathrm{Cd} \mathrm{g}^{-1}$ for mWTR, uWTR, and nWTR, respectively. The calculated Langmuir $q_{\max }$ value of nWTR was 17 and 10 times higher than $q_{\max }$ of mWTR in single- and multielement systems, respectively. Moreover, the high value of $K_{L}$ (Langmuir adsorption coefficient related to apparent energy of adsorption) showed that $\mathrm{Cd}$ was much better 


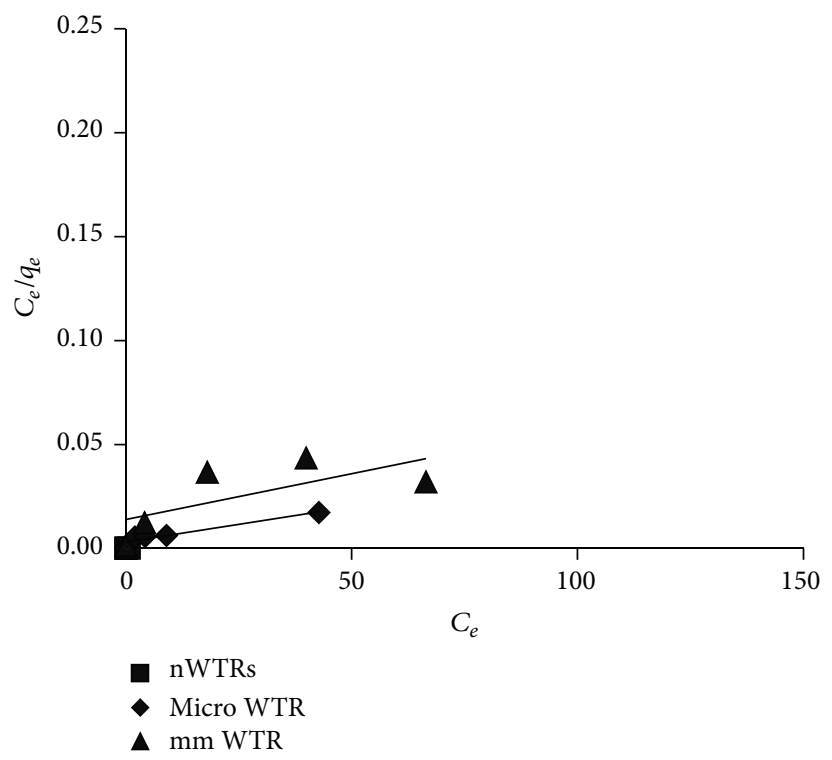

(a)

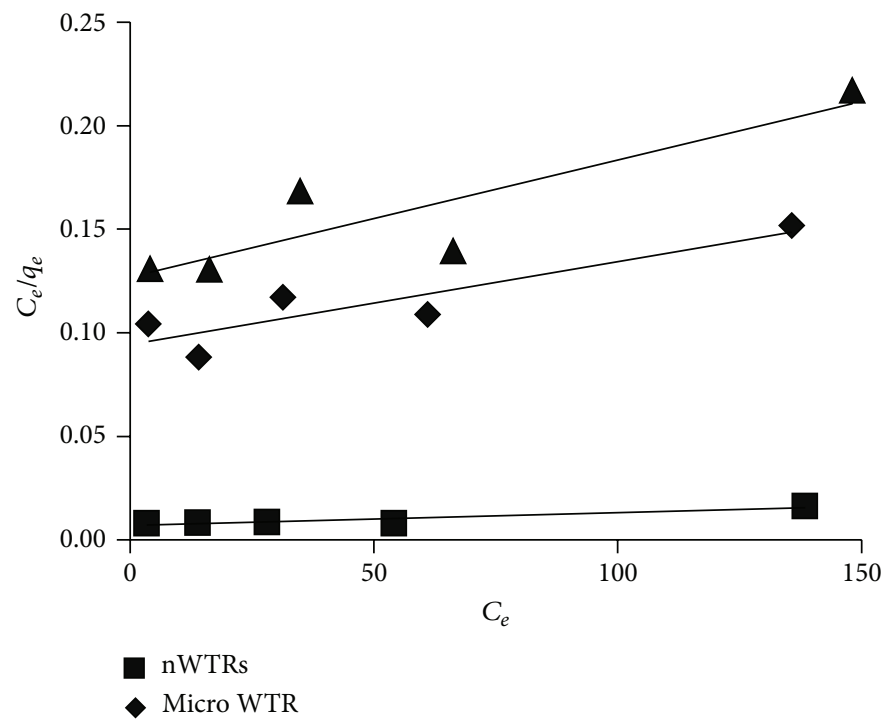

(b)

FIGURE 3: Langmuir isotherm for cadmium sorption by 3 different sizes of water treatment residuals in single-ion (a) and multi-ion (b) systems.

adsorbed onto the nWTR than mWTR and uWTR (Table 2). These results demonstrated that the nWTR is a superior sorbent for Cd in comparison to mWTR and uWTR. This could be explained on the basis of high and well-developed specific surface area of nWTR.

The competing effect of multi-ion system on Cd adsorption on nWTR was investigated by measuring the adsorption capacity ratio $(R)$ of $\mathrm{Cd}$ using the following formula [19]:

$$
R=\frac{q_{\text {multi }}}{q_{\text {single }}}
$$

where $q_{\text {multi }}$ and $q_{\text {single }}$ are the maximum amount of $\mathrm{Cd}$ adsorbed by nWTR in multi-ion and single-ion systems, respectively, and $R$ is the adsorption capacity ratio. When $R>1$, Cd adsorption is enhanced by the presence of other metal ions; when $R=1$, no interaction occurred; when $R<1, \mathrm{Cd}$ adsorption is suppressed by other metal ions. For all adsorbents studied, adsorption capacity ratios $(R)$ of $\mathrm{Cd}$ were less than 1 indicating the suppression of $\mathrm{Cd}$ adsorption due to the competition between $\mathrm{Cd}$ and the two ions $(\mathrm{Pb}$ and $\mathrm{Cu}$ ) in the multi-ion system for the same sorption sites.

3.4. Kinetic Studies. The results of kinetic studies on $\mathrm{Cd}$ adsorption at 3 different solution $\mathrm{pH}$ values are presented in Figure 4. The process of $\mathrm{Cd}$ removal using nanoscale WTR was rapid in the first $15 \mathrm{~min}$ and then slowed down considerably [20]. At initial solution $\mathrm{pH}$ 5, approximately $70 \%$ of Cd was adsorbed by nWTR within the first $15 \mathrm{~min}$ and slowly proceeded to $100 \%$ sorption by the end of the $24 \mathrm{~h}$ period. As can be seen from Figure 4, Cd removal by nWTR

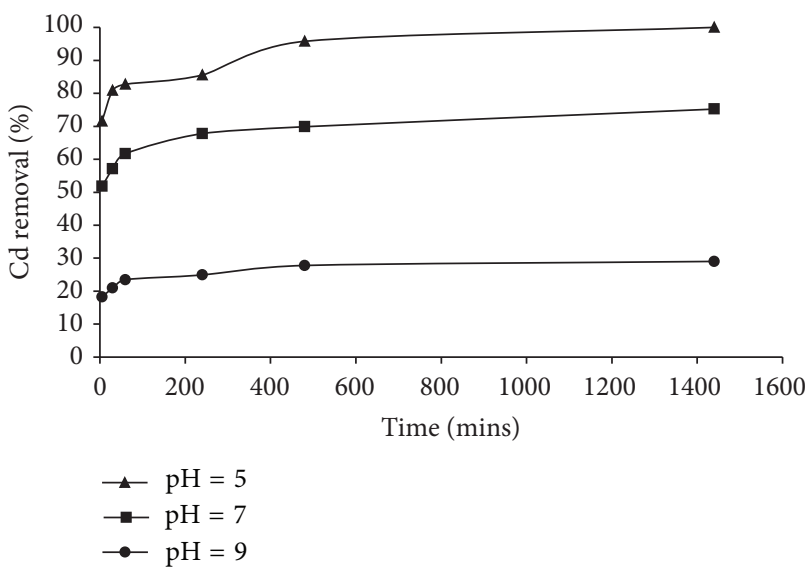

FIGURE 4: Kinetics of Cd removal by nWTRs at 3 different solution $\mathrm{pH}$ values.

decreased as the $\mathrm{pH}$ increased from 5 to 9 and a maximum value was reached at an equilibrium $\mathrm{pH}$ of around 5. In the aqueous solution, the metal ions may undergo hydrolysis and the metal adsorption process involved may present as follows [21]:

$$
\begin{aligned}
& \mathrm{M}^{2+}+n \mathrm{H}_{2} \mathrm{O}=\mathrm{M}\left(\mathrm{H}_{2} \mathrm{O}\right)_{n}{ }^{2+} \\
& \mathrm{M}\left(\mathrm{H}_{2} \mathrm{O}\right)_{n}{ }^{2+}=\left[\mathrm{M}\left(\mathrm{H}_{2} \mathrm{O}\right)_{n-1}(\mathrm{OH})\right]^{+}+\mathrm{H}^{+} \\
& \mathrm{M}^{2+}+n \mathrm{H}_{2} \mathrm{O} \stackrel{\mathrm{Ka}}{\longleftrightarrow}\left[\mathrm{M}\left(\mathrm{H}_{2} \mathrm{O}\right)_{n-1}(\mathrm{OH})\right]^{+}+\mathrm{H}^{+}
\end{aligned}
$$

$\mathrm{pKa}$ value for $\mathrm{Cd}(\mathrm{II})$ is 10.1 and $\mathrm{M}(\mathrm{OH})_{2}$ is the dominant species at $\mathrm{pH}>6.0$, while $\mathrm{M}^{2+}$ and $\mathrm{M}(\mathrm{OH})^{+}$are the dominant species at $\mathrm{pH}<6.0$. On further increase of $\mathrm{pH}$, adsorption 
TABLE 3: Kinetics model parameters and determination coefficients $\left(R^{2}\right)$ and standard error of estimate (SE) for cadmium adsorption by nWTR in single-ion and multi-ion systems at different initial solution $\mathrm{pH}$ values.

\begin{tabular}{|c|c|c|c|c|c|c|c|}
\hline \multirow{2}{*}{ Models } & \multirow{2}{*}{ Parameter } & \multicolumn{2}{|c|}{$\mathrm{pH} 5$} & \multicolumn{2}{|c|}{ pH 7} & \multicolumn{2}{|c|}{$\mathrm{pH} 9$} \\
\hline & & Single-ion & Multi-ion & Single-ion & Multi-ion & Single-ion & Multi-ion \\
\hline \multirow{4}{*}{ Elovich } & $\alpha \mathrm{mgg}^{-1} \mathrm{~min}^{-1}$ & $1.0 \times 10^{9}$ & 595876 & $1.1 \times 10^{8}$ & 552163 & $3.3 \times 10^{6}$ & 531042 \\
\hline & $\beta \mathrm{mgg}^{-1}$ & $2.3 \times 10^{-4}$ & $2 \times 10^{-3}$ & $3.0 \times 10^{-4}$ & $3 \times 10^{-3}$ & $6.0 \times 10^{-4}$ & $8 \times 10^{-3}$ \\
\hline & $R^{2}$ & 0.956 & 0.993 & 0.989 & 0.977 & 0.988 & 0.871 \\
\hline & SE & 2078 & 169 & 697 & 191 & 535 & 119 \\
\hline \multirow{4}{*}{ First-order } & $k_{a} \min ^{-1}$ & -0.409 & -0.004 & -0.384 & -0.003 & -0.726 & -0.002 \\
\hline & $a \mu \mathrm{gg}^{-1}$ & 10.53 & 7.797 & 10.27 & 7.405 & 10.50 & 6.654 \\
\hline & $R^{2}$ & 0.805 & 0.95 & 0.977 & 0.948 & 0.961 & 0.933 \\
\hline & SE & 0.237 & 0.225 & 0.226 & 0.161 & 0.211 & 0.127 \\
\hline \multirow{4}{*}{ Parabolic diffusion } & $k_{d} \mu \mathrm{gg}^{-1} \min ^{-1 / 2}$ & 4199 & 76.86 & 3575 & 51.57 & 1681 & 22.83 \\
\hline & $a \mu \mathrm{gg}^{-1}$ & 52113 & 4788 & 37087 & 3091 & 12783 & 1326 \\
\hline & $R^{2}$ & 0.956 & 0.796 & 0.989 & 0.891 & 0.988 & 0.964 \\
\hline & SE & 3111 & 557 & 2672 & 255 & 1409 & 60 \\
\hline \multirow{4}{*}{ Power function } & $k \mathrm{mgg}^{-1}$ & 1.0 & 1.0 & 1.0 & 1.0 & 1.0 & 1.0 \\
\hline & $v \min ^{-1}$ & 0.027 & 0.078 & 0.031 & 0.075 & 0.040 & 0.069 \\
\hline & $R^{2}$ & 0.955 & 0.889 & 0.982 & 0.920 & 0.975 & 0.892 \\
\hline & SE & 0.012 & 0.016 & 0.005 & 0.011 & 0.012 & 0.025 \\
\hline
\end{tabular}

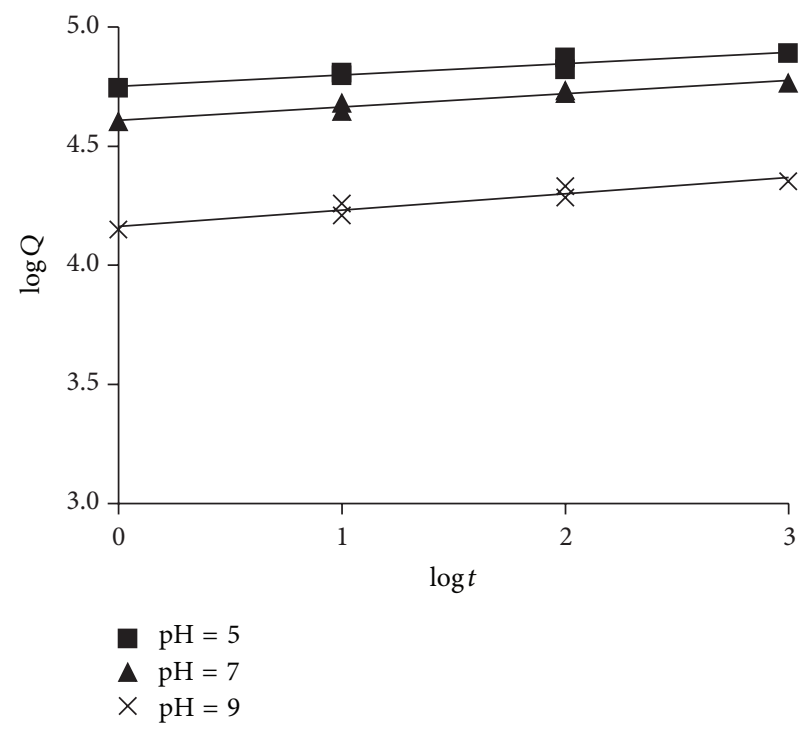

(a)

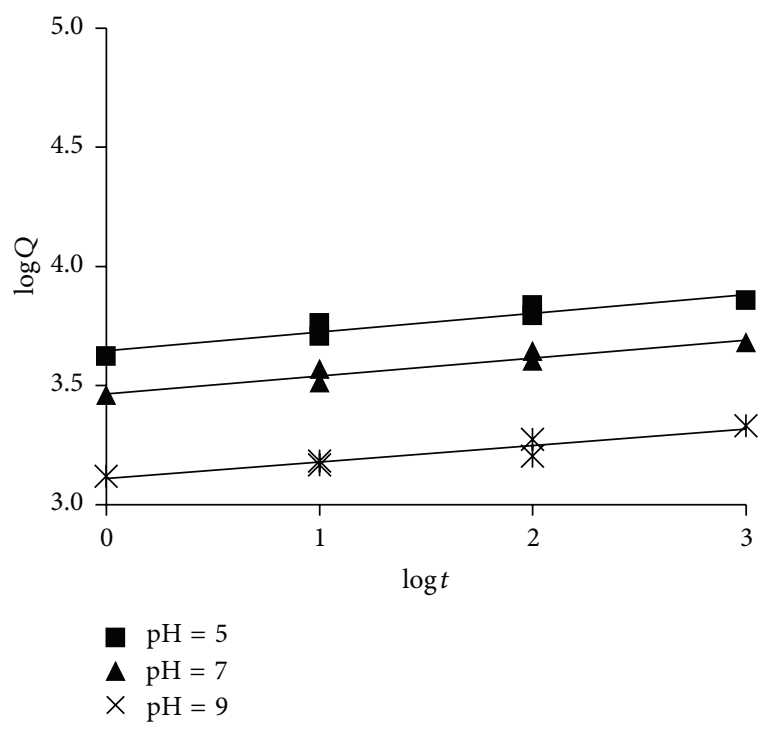

(b)

FIGURE 5: Power function model for cadmium sorption by nWTR in single-ion (a) and multi-ion (b) systems at different pH values.

decreases due to the formation and precipitation of cadmium hydroxide [22].

The kinetically driven $\mathrm{Cd}$ adsorption data at three $\mathrm{pH}$ solution values (5, 7, and 9) were fitted to four kinetic models [23] (Equilibrium and Kinetic Models) to predict Cd adsorption rate and understand the mechanism of adsorption process. The $\mathrm{Cd}$ adsorption data best fitted to power function and first-order kinetic models as the determination coefficients $R^{2}$ were quite high (significant at $p<0.01$ ) and SE values were the lowest (Table 3 ). The high SE values of Elovich and parabolic diffusion models indicated their low predictive capability to describe Cd adsorption by nWTRs. Therefore, based on SE values, power function model is considered the most suitable model to describe Cd adsorption on nWTR (Figure 5). The power function model is empirical and can successfully be used to compare experimental results. The estimated apparent sorption rates of the power function model $(v)$ for Cd adsorption from single-ion and multi-ion solutions are listed in Table 3 . The $(v)$ values could be related to the empirical rate coefficients $(k)$ of the overall sorption processes over the entire reaction time range [24]. As can be seen in Table 2, the presence of the competing ions $(\mathrm{Pb}$ and $\mathrm{Cu}$ ) greatly affected the estimated apparent sorption rate $(v)$. The estimated $v$ values for $\mathrm{Cd}$ in single-ion solutions 


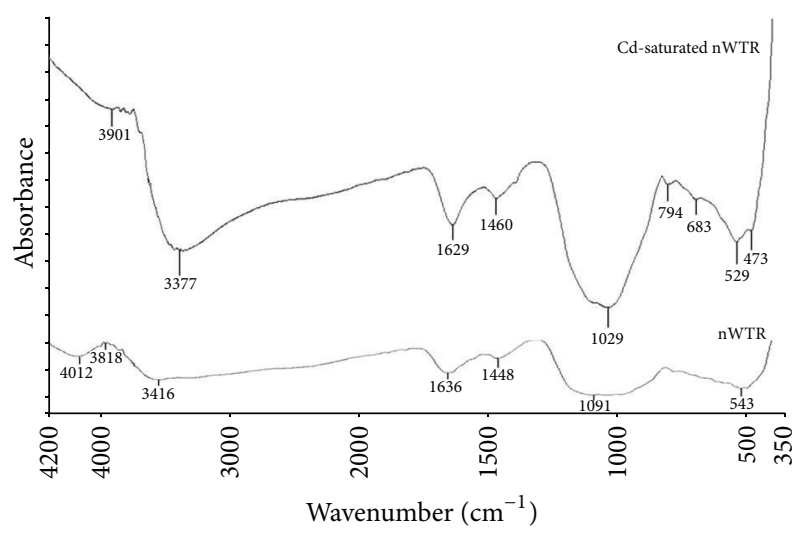

FIGURE 6: Fourier transmission infrared (FTIR) spectrum of nWTR before and after Cd adsorption.

were consistently higher than for $\mathrm{Cd}$ in multi-ion solutions indicating competition between $\mathrm{Cd}, \mathrm{Pb}$, and $\mathrm{Cu}$ for nWTR sorption sites. The decreased Cd adsorption by nWTR in the multi-ion system can be explained by considering the properties the other elements present. Some properties of the metal ion are (i) electronegativity, (ii) charge to radius ratio, (iii) abilities to form hydroxo complexes, and (iv) preferred adsorption site on the adsorbent. In our multielement system (Cd-Pb-Cu system), $\mathrm{Cd}(\mathrm{II})$ adsorption was suppressed as $\mathrm{Cu}$ and $\mathrm{Pb}$ form the most stable monohydroxo complexes and the least soluble hydroxides which have tendencies to adsorb more preferably than $\mathrm{Cd}(\mathrm{II})$, thereby inhibiting $\mathrm{Cd}(\mathrm{II})$ adsorption $[25,26]$. From these results, it is clear that $\mathrm{Cd}(\mathrm{II})$ adsorption behavior is significantly affected by the presence of competing ions ( $\mathrm{Pb}$ and copper). Therefore, the competitive sorption should be considered to assess the potential removal of $\mathrm{Cd}$ from aqueous solutions.

3.5. Fourier Transmission Infrared (FTIR) Spectrum of nWTR. FTIR spectroscopic analysis was performed with FTIR spectrophotometer model 4400 (Shimadzu Corporation, Japan) to investigate the adsorption mechanism of Cd onto nWTR. Solid adsorbent was mixed with $\mathrm{KBr}$ in 1:10 ratio and pressed under 10-ton pressure into pellet and the infrared spectra were measured. The FTIR spectra of nWTR before and after $\mathrm{Cd}$ adsorption are demonstrated in Figure 6. Before $\mathrm{Cd}$ adsorption, the two bands at $4012 \mathrm{~cm}^{-1}$ and $3416 \mathrm{~cm}^{-1}$ on nWTR surface correspond to $\mathrm{O}-\mathrm{H}$ bending vibrations, while the $1634 \mathrm{~cm}^{-1}$ band can be ascribed to the bending mode of $\mathrm{H}-\mathrm{O}-\mathrm{H}$ molecule $[27,28]$. In addition, the FTIR spectrum showed a small band at $543 \mathrm{~cm}^{-1}$ (O-AL$\mathrm{O}$ stretching vibration) and a medium band at $1090 \mathrm{~cm}^{-1}$ which can be assigned to bending vibration of $\mathrm{FeOH}$ modes of feroxyhyte [29, 30]. Retention of Cd on the surface of nWTR leads to significant spectral changes. The band at $4012 \mathrm{~cm}^{-1}$ (O-H bending vibration) completely disappeared which ascertained the participation of the surface hydroxyl group on the surface of nWTR (Figure 6). Increase in intensities and shift of locations of the $3416 \mathrm{~cm}^{-1}$ band to $3377 \mathrm{~cm}^{-1}$ (O-H bending vibrations), $1636 \mathrm{~cm}^{-1}$ to $1629 \mathrm{~cm}^{-1}$

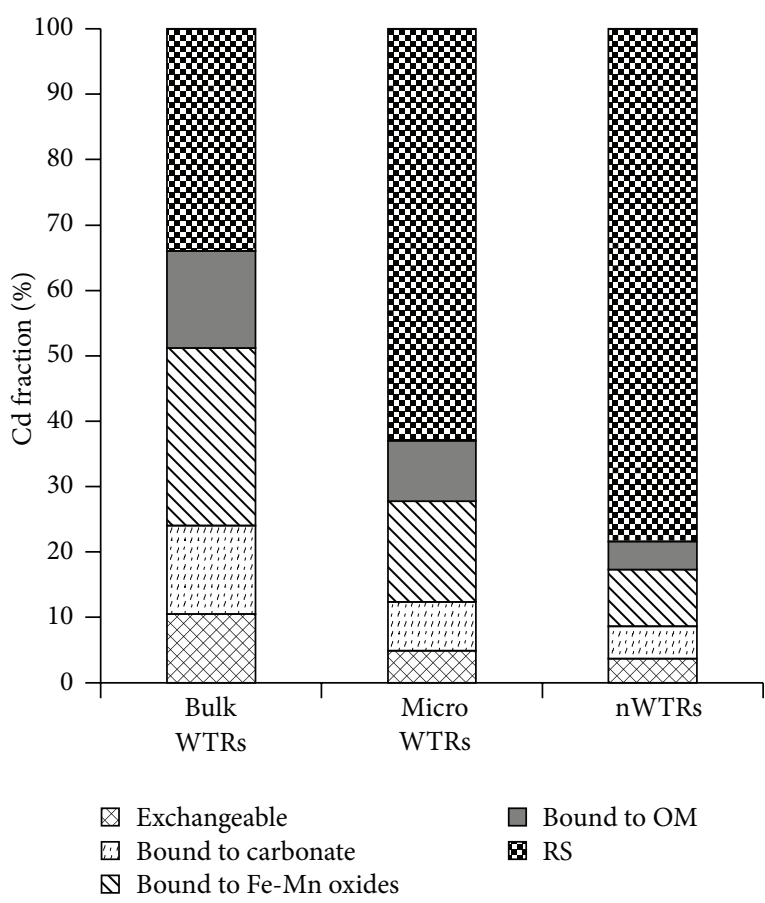

FIGURE 7: Fractionation of adsorbed cadmium on different particle sizes of WTR.

(assigned to $\mathrm{H}_{2} \mathrm{O}$ bending vibrations), $1091 \mathrm{~cm}^{-1}$ to $1029 \mathrm{~cm}^{-1}$ (corresponding to bending vibration of $\mathrm{FeOH}$ modes of feroxyhyte), and $543 \mathrm{~cm}^{-1}$ to $529 \mathrm{~cm}^{-1}$ (O-AL-O stretching vibration [31]) are noticed. Meanwhile, two new bands indicative of $\mathrm{d}^{\prime}-\mathrm{FeOOH}$ appeared at $794 \mathrm{~cm}^{-1}$ and $683 \mathrm{~cm}^{-1}$ $[31,32]$. The band position shift and intensities increase of the previously mentioned bands are clear indication of the level of specific molecular interaction. Therefore, the participation of $\mathrm{OH}, \mathrm{O}-\mathrm{Al}-\mathrm{O}, \mathrm{FeOH}$, and $\mathrm{FeOOH}$ entities in the adsorption process is suggested

3.6. Fractionation of Cd-Loaded $n W T R$ and Cd Mobility. To evaluate the potential mobility of adsorbed Cd onto nWTR relative to mWTR and uWTR, the Cd distribution in the fractions of the $\mathrm{Cd}(\mathrm{II})$-loaded adsorbents was performed using the fractionation scheme of Tessier et al. [33]. The sequential extractions have been commonly used for $\mathrm{Cd}$ speciation because of the efficiency and reproducibility of the procedure [33]. According to the scheme, the labile Cd associated with the residual (RS) fraction is less mobile than $\mathrm{Cd}$ associated with the nonresidual (NORS) fraction (sum of all fractions except the residual fraction). Such an approach enables us to correlate the $\mathrm{Cd}(\mathrm{II})$ data with adsorbent fractions and identify the mobility of $\mathrm{Cd}$ bound to different sorbent fractions. The Cd fractionation results (Figure 7) show that Cd adsorbed on mWTR was mostly associated with the more mobile NORS fraction (66\%), whereas $78.4 \%$ of Cd on nWTR was associated with the RS fraction, the less mobile fraction. Such differences could be related to particle size and crystalline effects, which in turn affect the solubility of $\mathrm{Cd}$ phases, present [34]. A greater percentage of $\mathrm{Cd}$ associated with the residual fraction of 


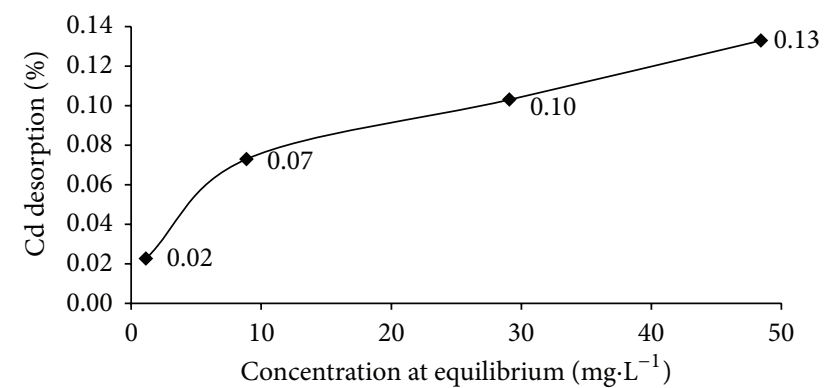

FIGURE 8: Desorption of Cd from nWTR (0.1 g) loaded with different Cd concentrations.

nWTR relative to mWTR and uWTR indicates the higher capability of nWTR to immobilize Cd compared to bulk WTR (mWTR). These observations support the hypothesis that the smaller size and the higher surface area of WTR nanoparticles greatly enhance its sorptive characteristics and stability.

3.7. Stability of Cd-nWTR Surface Complexes. The percentages of $\mathrm{Cd}$ desorbed from Cd-loaded nWTR are shown in Figure 8. The amounts of Cd released increased from 0.02 to $0.13 \%$ as the Cd concentrations increased from 5 to $500 \mathrm{mg} / \mathrm{L}$ (at $\mathrm{pH}$ 7.0). It is clear that the Cd adsorbed on nWTR was not altered as less than $0.2 \%$ of adsorbed Cd(II) was released at the highest $\mathrm{Cd}$ concentration load after 4 consecutive desorption cycles. These results suggest the stability of $\mathrm{Cd}$ nWTR surface complexes.

\subsection{Efficiency of Cadmium (II) Removal from Wastewater.} The efficiency of nWTR for Cd(II) removal was determined by conducting a batch experiment on real wastewater. Four samples were collected from wastewater discharged from fruit and vegetable processing plant by using polyethylene bottles. The wastewater was characterized in terms of $\mathrm{pH}$, conductivity, Cd concentration, and major and minor elements. One liter of each water sample was spiked with $100 \mathrm{mg} / \mathrm{L}^{-1}$ of $\mathrm{Cd}^{+2}$ and $25 \mathrm{~mL}$ was placed in $50 \mathrm{~mL}$ falcon tube along with $0.1 \mathrm{~g}$ nWTR. The mixture was shaken for $2 \mathrm{~h}$ and centrifuged at $4000 \mathrm{rpm}$ for $20 \mathrm{~min}$ and the supernatant solutions were filtered and analyzed for Cd by ICPS.

The $\mathrm{pH}$ and conductivity of the wastewater were 8.1 and $3.11 \pm 0.11 \mathrm{ds} \mathrm{m}^{-1}$, respectively. The predominant anions in the water were chloride $\left(22.15 \pm 1.65 \mathrm{mg} \mathrm{L}^{-1}\right)$, nitrate $(18.09 \pm$ $\left.2.54 \mathrm{mg} \mathrm{L}^{-1}\right)$, and phosphate $\left(6.55 \pm 0.33 \mathrm{mg} \mathrm{L}^{-1}\right)$ and the sodium adsorption ratio (SAR) was $6.12 \pm 0.89$. Amounts of $\mathrm{Cu}\left(0.09 \pm 0.01 \mathrm{mg} \mathrm{L}^{-1}\right), \mathrm{Cd}\left(0.04 \pm 0.002 \mathrm{mg} \mathrm{L}^{-1}\right), \mathrm{Cr}(0.40 \pm$ $0.03)$, As $\left(3.00 \pm 0.09 \mathrm{mg} \mathrm{L}^{-1}\right)$, and $\mathrm{Pb}\left(2.22 \pm 0.05 \mathrm{mg} \mathrm{L}^{-1}\right)$ were also detected. The real efficiency of nWTR for Cd removal from wastewater samples studied was calculated and found to be $98.35 \%$. These results highlight the potential of nWTR for heavy metals removal from wastewater.

\section{Conclusions}

Nanoparticles of water treatment residuals demonstrated high removal efficiency of $\mathrm{Cd}(\mathrm{II})$ from aqueous solutions under various sets of experimental conditions. However, Cd(II) adsorption by nWTR was much higher in single-ion system than in multi-ion system due to the competition of $\mathrm{Pb}^{+2}$ and $\mathrm{Cu}^{+2}$ ions with $\mathrm{Cd}^{2+}$ ions. The $\mathrm{Cd}(\mathrm{II})$ adsorption mechanism seems to be related to the interaction between $\mathrm{Cd}(\mathrm{II})$ and $\mathrm{OH}, \mathrm{O}-\mathrm{Al}-\mathrm{O}, \mathrm{FeOH}$, and $\mathrm{FeOOH}$ entities. The real efficiency of nWTR for Cd removal from wastewater samples was found to be $98.35 \%$. Therefore, it is expected that the obtained nWTR can be used as potential sorbents for the removal of various toxic pollutants from wastewater.

\section{Competing Interests}

The authors declare that there are no competing interests regarding the publication of this paper.

\section{Acknowledgments}

The authors gratefully acknowledge the financial support from the Egyptian Science and Technology Development Fund (STDF 4977-2013).

\section{References}

[1] P. K. Rai, "Heavy metal pollution in aquatic ecosystems and its phytoremediation using wetland plants: an eco-sustainable approach," International Journal of Phytoremediation, vol. 10, no. 2, pp. 131-158, 2008.

[2] G. Drasch, M. Horvat, and M. Stoeppler, "Mercury," in Elements and Their Compounds in the Environment: Occurrence, Analysis and Biological Relevance, E. Merian, M. Anke, M. Ihnat, and M. Stoeppler, Eds., vol. 2, pp. 931-1005, Wiley-VCH, Weinheim, Germany, 2004.

[3] R. L. Chaney, "Cadmium and zinc", in Trace Elements in Soils, P. S. Hooda, Ed., chapter 17, John Wiley \& Sons, Chichester, UK, 2010.

[4] B. J. Alloway, Heavy Metals in Soils, John Wiley \& Sons, New York, NY, USA, 1995.

[5] O. B. Akpor and M. Muchie, "Remediation of heavy metals in drinking water and wastewater treatment systems: processes and applications," International Journal of Physical Sciences, vol. 5, no. 12, pp. 1807-1817, 2010.

[6] C. G. Rocha, D. A. M. Zaia, R. V. D. S. Alfaya, and A. A. D. S. Alfaya, "Use of rice straw as biosorbent for removal of $\mathrm{Cu}(\mathrm{II})$, $\mathrm{Zn}(\mathrm{II}), \mathrm{Cd}(\mathrm{II})$ and $\mathrm{Hg}(\mathrm{II})$ ions in industrial effluents," Journal of Hazardous Materials, vol. 166, no. 1, pp. 383-388, 2009.

[7] N. Savage and M. S. Diallo, "Nanomaterials and water purification: opportunities and challenges," Journal of Nanoparticle Research, vol. 7, no. 4, pp. 331-342, 2005.

[8] R. P. Schwarzenbach, B. I. Escher, K. Fenner et al., "The challenge of micropollutants in aquatic systems," Science, vol. 313, no. 5790, pp. 1072-1077, 2006.

[9] D. Sarkar, K. C. Makris, V. Vandanapu, and R. Datta, "Arsenic immobilization in soils amended with drinking-water treatment residuals," Environmental Pollution, vol. 146, no. 2, pp. 414-419, 2007.

[10] E. A. Elkhatib, A. M. Mahdy, and M. M. ElManeah, "Effects of drinking water treatment residuals on nickel retention in soils: a macroscopic and thermodynamic study," Journal of Soils and Sediments, vol. 13, no. 1, pp. 94-105, 2013. 
[11] E. A. Elkhatib and M. L. Moharem, "Immobilization of copper, lead, and nickel in two arid soils amended with biosolids: effect of drinking water treatment residuals," Journal of Soils and Sediments, vol. 15, no. 9, pp. 1937-1946, 2015.

[12] A. Hovsepyan and J.-C. J. Bonzongo, "Aluminum drinking water treatment residuals (Al-WTRs) as sorbent for mercury: implications for soil remediation," Journal of Hazardous Materials, vol. 164, no. 1, pp. 73-80, 2009.

[13] A. G. Caporale, P. Punamiya, M. Pigna, A. Violante, and D. Sarkar, "Effect of particle size of drinking-water treatment residuals on the sorption of arsenic in the presence of competing ions," Journal of Hazardous Materials, vol. 260, pp. 644-651, 2013.

[14] E. A. Elkhatib, A. M. Mahdy, and K. A. Salama, "Green synthesis of nanoparticles by milling residues of water treatment," Environmental Chemistry Letters, vol. 13, no. 3, pp. 333-339, 2015.

[15] E. Elkhatib, A. Mahdy, F. Sherif, and H. Hamadeen, "Evaluation of a novel water treatment residual nanoparticles as a sorbent for arsenic removal," Journal of Nanomaterials, vol. 2015, Article ID 912942, 10 pages, 2015.

[16] J. A. Ippolito, K. A. Barbarick, and H. A. Elliott, "Drinking water treatment residuals: a review of recent uses," Journal of Environmental Quality, vol. 40, no. 1, pp. 1-12, 2011.

[17] C. H. Giles, T. H. MacEwan, S. N. Nakhwa, and D. Smith, "786. Studies in adsorption. Part XI. A system of classification of solution adsorption isotherms, and its use in diagnosis of adsorption mechanisms and in measurement of specific surface areas of solids," Journal of the Chemical Society, vol. 111, pp. 3973-3993, 1960.

[18] K. Y. Foo and B. H. Hameed, "Insights into the modeling of adsorption isotherm systems," Chemical Engineering Journal, vol. 156, no. 1, pp. 2-10, 2010.

[19] D. Mohan, C. U. Pittman Jr., and P. H. Steele, "Single, binary and multi-component adsorption of copper and cadmium from aqueous solutions on Kraft lignin-a biosorbent," Journal of Colloid and Interface Science, vol. 297, no. 2, pp. 489-504, 2006.

[20] L. J. Glover II, M. J. Eick, and P. V. Brady, "Desorption kinetics of cadmium ${ }^{2+}$ and lead ${ }^{2+}$ from goethite: influence of time and organic acids," Soil Science Society of America Journal, vol. 66, no. 3, pp. 797-804, 2002.

[21] G. Wulfsberg, Principles of Descriptive Chemistry, Brookes/Cole Publishing, Montery, Calif, USA, 1987.

[22] T. K. Naiya, A. K. Bhattacharya, and S. K. Das, "Adsorption of $\mathrm{Cd}(\mathrm{II})$ and $\mathrm{Pb}(\mathrm{II})$ from aqueous solutions on activated alumina," Journal of Colloid and Interface Science, vol. 333, no. 1, pp. 14-26, 2009.

[23] E. A. Elkhatib, O. L. Bennett, and R. J. Wright, "Kinetics of arsenite sorption in soils," Soil Science Society of America Journal, vol. 48, no. 4, pp. 758-762, 1984.

[24] S. Serrano, F. Garrido, C. G. Campbell, and M. T. GarcíaGonzález, "Competitive sorption of cadmium and lead in acid soils of Central Spain," Geoderma, vol. 124, no. 1-2, pp. 91-104, 2005.

[25] M. Mohapatra, L. Mohapatra, P. Singh, S. Anand, and B. Mishra, "A comparative study on $\mathrm{Pb}(\mathrm{II}), \mathrm{Cd}(\mathrm{II}), \mathrm{Cu}(\mathrm{II}), \mathrm{Co}(\mathrm{II})$ adsorption from single and binary aqueous solutions on additive assisted nano-structured goethite," International Journal of Engineering, Science and Technology, vol. 2, no. 8, 2011.

[26] R.-S. Juang and J.-Y. Chung, "Equilibrium sorption of heavy metals and phosphate from single- and binary-sorbate solutions on goethite," Journal of Colloid and Interface Science, vol. 275, no. 1, pp. 53-60, 2004.
[27] M. Gotić, S. Musić, S. Popović, and L. Sekovanić, "Investigation of factors influencing the precipitation of iron oxides from $\mathrm{Fe}(\mathrm{II})$ containing solutions," Croatica Chemica Acta, vol. 81, no. 4, pp. 569-578, 2008.

[28] H. D. Ruan, R. L. Frost, J. T. Kloprogge, and L. Duong, "Infrared spectroscopy of goethite dehydroxylation: III. FT-IR microscopy of in situ study of the thermal transformation of goethite to hematite," Spectrochimica Acta-Part A, vol. 58, no. 5, pp. 967-981, 2002.

[29] M. Gotić, S. Popović, and S. Musić, "Formation and characterization of $\delta$-FeOOH," Materials Letters, vol. 21, no. 3-4, pp. 289295, 1994.

[30] L. Carlson and U. Schwertmann, "Natural occurrence of feroxyhite (del'-FeOOH)," Clays \& Clay Minerals, vol. 28, no. 4, pp. 272-280, 1980.

[31] T. K. Sen and M. V. Sarzali, "Removal of cadmium metal ion $\left(\mathrm{Cd}^{2+}\right)$ from its aqueous solution by aluminium oxide $\left(\mathrm{Al}_{2} \mathrm{O}_{3}\right)$ : a kinetic and equilibrium study," Chemical Engineering Journal, vol. 142, no. 3, pp. 256-262, 2008.

[32] L. Mei, L. Liao, Z. Wang, and C. Xu, "Interactions between phosphoric/tannic acid and different forms of $\mathrm{FeOOH}$," Advances in Materials Science and Engineering, vol. 2015, Article ID 250836, 10 pages, 2015.

[33] A. Tessier, P. G. C. Campbell, and M. Blsson, "Sequential extraction procedure for the speciation of particulate trace metals," Analytical Chemistry, vol. 51, no. 7, pp. 844-851, 1979.

[34] H. K. Okoro, O. S. Fatoki, F. A. Adekola, B. J. Ximba, and R. G. Snyman, "A review of sequential extraction procedures for heavy metals speciation in soil and sediments," Scientific Reports, vol. 1, no. 3, article 181, 2012. 

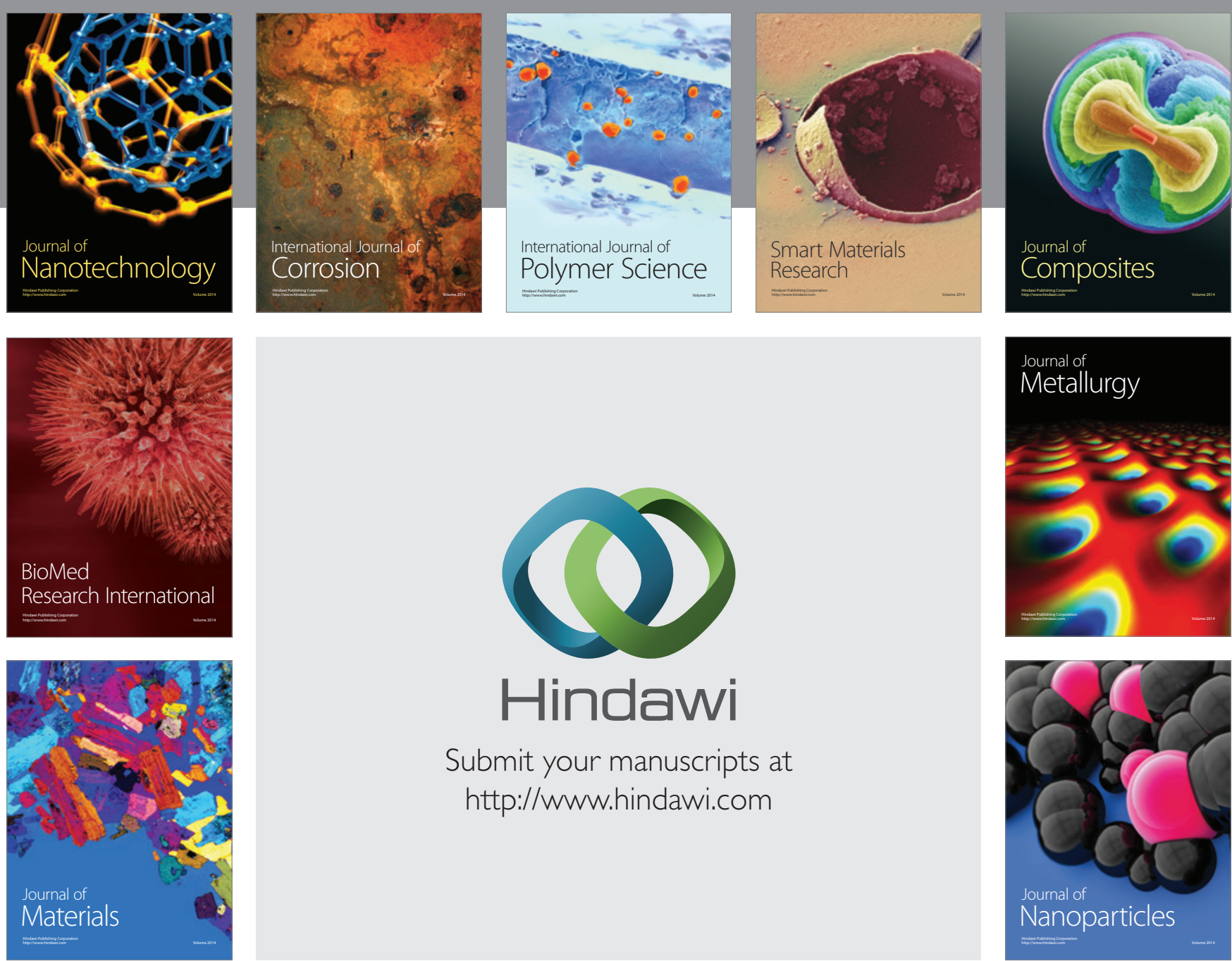

\section{Hindawi}

Submit your manuscripts at

http://www.hindawi.com

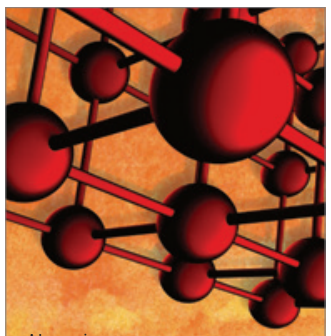

Materials Science and Engineering
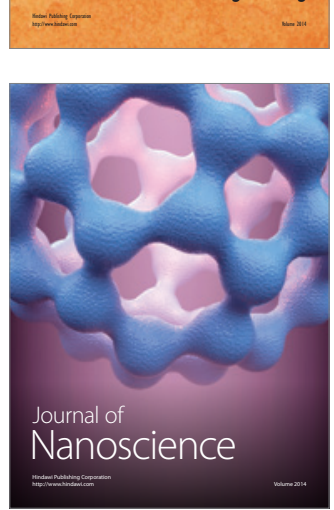
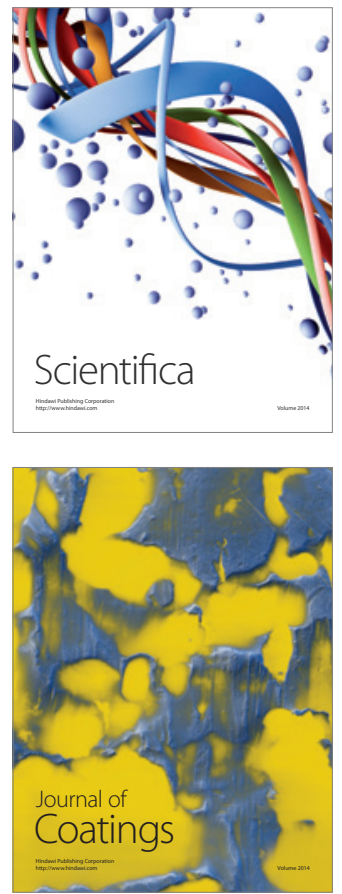
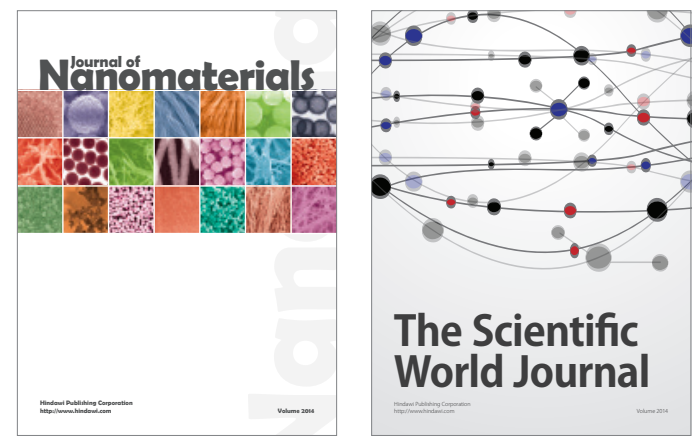

The Scientific World Journal
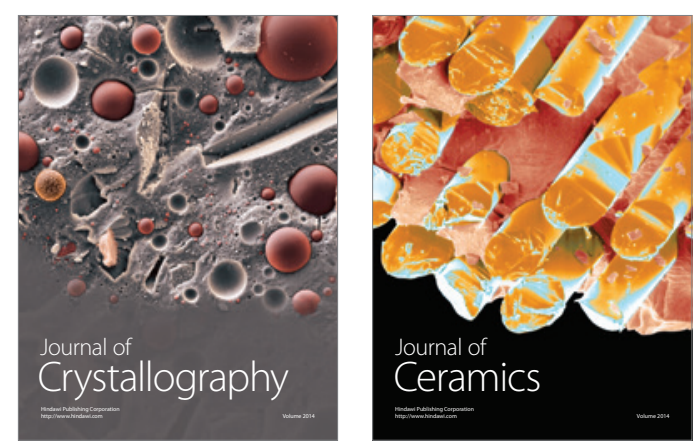
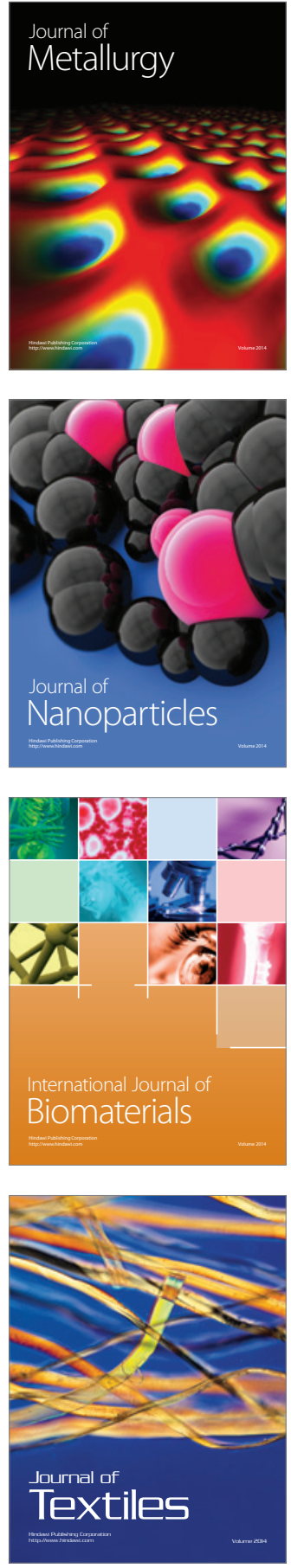